 Investigaciones de Educación, N. 63. Segundo semestre de 2012, Bogotá, Colombia. lombia.

\title{
Cine, pensamiento y estética: reflexiones filosóficas y educativas
}

//Movies, thought, and aesthetics Some philosophy and education meditations

//Cinema, pensamento e estética: reflexões filosóficas e educativas

\section{Diana Milena Peñuela C. Óscar Pulido Cortés*}

\section{Resumen}

El presente artículo aporta algunas discusiones en torno a la relación cine y educación, como continuidad a un proyecto de investigación realizado alrededor de la relación cine-pedagogía y pensamiento. En su proceso escritural se ubican tres campos analíticos: el primero intenta mostrar algunos conceptos del cine como percepción, representación, estética y pensamiento desde la perspectiva de dos autores: Walter Benjamin y Gilles Deleuze, a partir de una mirada filosófica; el segundo posiciona elementos para una discusión contemporánea de la relación entre cine, educación y pensamiento $y$, finalmente, el tercer campo da cuenta de algunas regularidades de uso del cine en el campo educativo.

\section{Abstract}

This paper provides some discussions about movies and education relationship as a steady research project focused on movies- thinking-pedagogy. This process shows three analytical realms: first, some movie concepts, such as perception, representation, aesthetics and thought by two authors, Walter Benjamin and Gilles Deleuze, from a philosophical standpoint; second, other position issues for a contemporary discussion of relationship between movies, education and thought; and finally, some common uses of movies in education.

\section{Resumo}

O presente artigo traz algumas discussões em torno da relação cinema e educação, em continuidade a um projeto de investigação realizado sobre a relação cinema-pedagogia e pensamento. Em seu processo de escrita se situam três campos analíticos: o primeiro intenta mostrar alguns conceitos do cinema, tais como: percepção, representação, estética e pensamento, na perspectiva de dois autores, Walter Benjamin e Gilles Deleuze, a partir de uma ótica filosófica; o segundo posiciona elementos para uma discussão contemporânea da relação entre cinema, educação e pensamento; e, finalmente, o terceiro campo dá conta de algumas regularidades do uso do cinema no campo educativo.

\section{Palabras Clave}

Imagen-pensamiento, cine, estética, educación.

\section{Keywords}

Picture-thinking, movies, aesthetics, education.

\section{Palavras chave}

Imagem-pensamento, cinema, estética, educação 
¿Cuál es la relación que se puede establecer entre el cine y los procesos de producción de pensamiento y las posibilidades de formación en el campo educativo? ¿De qué maneras se invierten los procesos de enseñanza-aprendizaje en el campo educativo mediante el uso del cine? ¿Cómo desplazar las regularidades de uso del cine más allá de la innovación educativa y los procesos de instrumentalización y didactización acrítica que han devenido prácticas instituidas? Estos son algunos de los cuestionamientos que genera la escritura del presente artículo.

Históricamente, el cine ha posibilitado puntos de encuentro con la filosofía, apareciendo en el uso y la presentación de algunos autores o problemas que tienen que ver con la filosofía y las humanidades, es decir, estas intenciones se describen en forma de ficción cinematográfica y permiten la aproximación a los problemas, temas, autores y contingencias de los contenidos abordados en el escenario educativo, esto es, el cine, la filosofía y la pedagogía como forma de pensamiento se encuentran, potencian y constituyen sujetos. En los dos primeros campos analíticos de este escrito se da cuenta de las relaciones que se pueden establecer entre cine-filosofía y cine-educación.

Al mismo tiempo, el cine como forma de pensamiento contemporáneo ha sido utilizado en cuanto medio que posibilita experiencias y relaciones sensibles con escenarios diversos, es así como en los procesos educativos suscita un encuentro que permite devenires y retroalimentaciones mutuas, es decir, en determinadas acciones y momentos la educación deviene cine y el cine deviene educación en un encuentro fascinante y posibilitador de constitución y acción sobre los sujetos que aprenden, que enseñan, que enseñan aprendiendo y que aprenden enseñando. El cine llega a la escuela y a la universidad para ser usado como forma de enseñanza, además es usado también en pedagogía para la formación de maestros y para el fortalecimiento de experiencias de aula con estudiantes, como se muestra en el tercer campo analítico del presente artículo, que se presenta a manera de conclusiones. 


\section{Primer campo analítico: cine y filosofia, apuestas críticas desde Benjamin y Deleuze}

\section{Reproductibilidad, cine y estética: una mirada crítica desde Walter Benjamin}

Benjamin (1989) sitúa históricamente los distintos procesos de reproductibilidad técnica, desde la reproducción técnica del dibujo hasta llegar a la reproducción técnica del sonido con la emergencia del cine sonoro; en su concepto, la reproducción técnica del dibujo se da a través de la xilografía y la litografía, la de la escritura mediante la imprenta, la de la imagen a través de la fotografía; también posiciona cómo en el proceso de reproducción plástica "el ojo es más rápido captando que la mano dibujando; por eso se ha apresurado tantísimo el proceso de la reproducción plástica que ya puede ir a paso con la palabra hablada" (p. 2); en relación con la reproducción técnica del sonido muestra cómo "en la litografía se escondía virtualmente el periódico ilustrado y en la fotografía el cine sonoro, así la reproducción técnica del sonido fue empresa acometida a finales del siglo pasado" (ibíd.).

De igual forma, expone cómo históricamente la época de la reproductibilidad técnica desligó al arte de su fundamento cultural y provocó la extinción de su autonomía. Además, evidencia las dificultades de la estética tradicional, primero con la fotografía y luego con el cine, "en vano se aplicó por de pronto mucha agudeza para decidir si la fotografía es un arte (sin plantearse la cuestión previa sobre si la invención de la primera no modificaba por entero el carácter del segundo). En seguida se encargaron los teóricos del cine de hacer el correspondiente y precipitado planteamiento" (Benjamin, 1989 , p. 8). Así pues, en términos del autor, "resulta muy instructivo ver cómo, obligados por su empeño en ensamblar el cine en el arte, esos teóricos ponen en su interpretación, y por cierto sin reparo de ningún tipo, elementos culturales" (ibíd.). Critica entonces la "lucha del cine por el ascenso al reino del arte".

De otra parte, sitúa la relación problemática entre imagen y reproducción, en su concepto "la cercanía de la imagen en la copia y en la reproducción lleva a su extinción" pues "cada día cobra una vigencia más irrecusable la necesidad de adueñarse de los objetos en la más próxima de las cercanías, en la imagen, más bien en la copia, en la reproducción" (Benjamin, 1989, p. 4). En lugar de su fundamentación en un ritual aparece su fundamentación en una praxis distinta, a saber, en la política" (p. 6). Así pues, Benjamin critica los usos del arte, incluido el cine, para el fascismo, y busca proponer unos elementos de la teoría del arte que no sean útiles a los fines del fascismo y por el contrario sean "utilizables para la formación de exigencias revolucionaria en la política artística" (p. 1). 
No obstante, a pesar de su mirada crítica sobre las posibilidades y también alrededor de las cooptaciones del cine, el autor aborda varios puntos que generan miradas analíticas interesantes en relación con el cine:

\section{El problema del aquí y el ahora en la reproducción}

Benjamin (1989) plantea la existencia irrepetible del arte en el lugar en el que se encuentra, en su concepto:

Incluso en la reproducción mejor acabada falta algo: el aquí y ahora de la obra de arte, su existencia irrepetible en el lugar en que se encuentra. En dicha existencia singular, $y$ en ninguna otra cosa, se realizó la historia a la que ha estado sometida en el curso de su perduración" (p. 2).

Así pues, el aquí y ahora del original constituye el concepto de su autenticidad (p. 3), y uno de los problemas de la reproducción de una obra de arte, para el autor, es precisamente el desprecio por su aquí y ahora, lo cual nos devuelve al problema de su autenticidad, problema del que no es ajeno el cine. En sus palabras:

La autenticidad de una cosa es la cifra de todo lo que desde el origen puede transmitirse en ella desde su duración material hasta su testificación histórica. Como esta última se funda en la primera, que a su vez se le escapa al hombre en la reproducción, por eso se tambalea en esta la testificación histórica de la cosa (p. 3).

\section{El cine o de la exhibición del trabajo del actor por medio de un mecanismo}

El autor plantea que el actor de teatro presenta él mismo en persona al público su ejecución artística; por el contrario, la del actor de cine es presentada por medio de todo un mecanismo, de esta forma:

La actuación del actor está sometida por tanto a una serie de tests ópticos. Y esta es la primera consecuencia de que su trabajo se exhiba por medio de un me- 
canismo. La segunda consecuencia estriba en que este actor, puesto que no es él mismo quien presenta a los espectadores su ejecución, se ve mermado en la posibilidad, reservada al actor de teatro, de acomodar su actuación al público durante la función (...) Adopta su actitud: hace test, y no es esta una actitud a la que puedan someterse valores culturales (Benjamin, 1989, p. 9).

\section{El cine o de la pérdida de la} multiplicidad en la actuación

\section{del actor}

De acuerdo con Benjamin (1989), el teatro entra en crisis con la llegada del cine, con lo que "el arte se ha escapado del reino del halo de lo bello, único en el que se pensó por largo tiempo que podía alcanzar florecimiento" ( $p$. 11). Benjamin destaca la multiplicidad en la actuación del actor de teatro, en contraposición al actor de cine, pues en el primero "el artista que actúa en escena se transpone en un papel. Lo cual se le niega frecuentemente al actor de cine. Su ejecución no es unitaria, sino que se compone de muchas ejecuciones" (p. 10). Además, el actor del cine se representa a sí mismo ante el mecanismo, pues al cine no le importa que el actor represente ante el público un personaje (p. 9). En este sentido, al actor de cine también pierde su aura, dirá Benjamin.

He aquí un estado de cosas que podríamos caracterizar así: por primera vez-y esto es obra del cine_-llega el hombre a la situación de tener que actuar con toda su persona viva, pero renunciando a su aura. Porque el aura está ligada a su aquí y ahora. Del aura no hay copia (p. 10).

\section{El extrañamiento del actor de cine y su propia aparición en el espejo}

Para Benjamin, en su época se configura la transportación de la imagen del espejo ante el público (mercado) y la venta del cine como cualquier artículo de fábrica, expone que:

$\mathrm{Ni}$ un solo instante abandona al actor de cine la conciencia de ello. Mientras está frente a la cámara sabe que en última instancia es con el público con quien tiene que habérselas: con el público de consumidores que forman el mercado. Este mercado, al que 
va no solo con su fuerza de trabajo, sino con su piel, con sus entrañas todas, le resulta, en el mismo instante en que determina su actuación para él, tan poco asible como lo es para cualquier artículo que se hace en una fábrica (p. 11).

Critica también a la producción cinematográfica de Europa Occidental, por la relación que ha establecido entre capital cinematográfico y mercancía y en concepto, aunque "en ciertos casos pueda hoy el cine apoyar además una crítica revolucionaria de las condiciones sociales, incluso del orden de la propiedad", mientras sea el capital quien de en él el tono,

No podrá adjudicársele al cine actual otro mérito revolucionario que el de apoyar una crítica revolucionaria de las concepciones que hemos heredado sobre el arte. Claro que no discutimos que Pero no es este el centro de gravedad de la presente investigación (ni lo es tampoco de la producción cinematográfica de Europa occidental) (p. 11).

\section{Sobre el empobrecimiento en la percepción de lo real}

El autor posiciona el tema de la percepción de lo real y su condicionamiento histórico, pues en su concepto:

Dentro de grandes espacios históricos de tiempo se modifican, junto con toda la existencia de las colectividades humanas, el modo y manera de su percepción sensorial. Dichos modo y manera en que esa percepción se organiza, el medio en el que acontecen, están condicionados no solo natural, sino también históricamente (p. 4).

Plantea Benjamin que:

Tanto en el mundo óptico, como en el acústico, el cine ha traído consigo una profundización similar de nuestra apercepción. Pero esta situación tiene un reverso: las ejecuciones que expone el cine son plausibles de análisis mucho más exactos y más ricos en puntos de vista que el que se llevaría a cabo sobre las que se representan en la pintura o en la escena. El cine indica la situación de manera incomparablemente más precisa, y esto es lo que constituye su mayor susceptibilidad de análisis frente a la pintura (p. 15). 


\section{Imagen pensamiento en el cine: aportes desde el pensamiento deleuziano'}

Un análisis de las relaciones entre imagen-movimiento e imagentiempo que se generan desde una mirada analítica del cine son condiciones de posibilidad y de puesta en sincronía de la emergencia y visibilización de imágenes pensamiento que permiten romper los modelos tradicionales de construcción del mismo, es decir, los modelos de pensamiento hegemónico.

Deleuze (2001) explica el cine desde la filosofía a partir de dos nociones claves: imagen-movimiento, imagen-tiempo, las cuales son dos formas de cine según Vollet (2006):

Con las dos quiere a grosso modo explicar el cine hasta la Segunda Guerra Mundial como un cine que se concentra en acción y movimiento a diferencia del cine de posguerra, que se ha vuelto reflexivo y privilegia la presencia del tiempo (p. 70).

Así pues, la imagen-movimiento estaría concentrada en la acción y la

Proyecto de investigación titulado: "El cine como forma de pensamiento desde la pedagogía: una mirada a la formación de maestros", realizado en el periodo 2010-2011. Entre otros, participaron: Víctor Manuel Rodríguez, Angélica Osorio, Marcela Rodríguez, Cindy Johana Quintero, Andrea Hernández y Diana Milena Peñuela C., el informe se encuentra en proceso de publicación. imagen-tiempo en la reflexión: "La primera reproduce un movimiento en su entorno y la segunda, en cambio, resalta la importancia del tiempo por medio de la mera visión (o audición)" (p. 75). Antes de profundizar en las apropiaciones que realiza Vollet del pensamiento deleuziano al campo cinematográfico, se hará alusión a la imagen movimiento bergsoniana y sus tres variedades: la imagen acción, la imagen afección y la imagen percepción.

\section{La imagen movimiento y sus}

\section{tres variedades Bergson}

\section{Deleuze}

En busca de superar la dualidad entre la imagen-movimiento y entre la conciencia-cosa, discusión esta última desarrollada tanto por Husserl como por el mismo Bergson, el primero cuando plantea que: toda conciencia es conciencia de algo y el segundo en tanto propone que toda conciencia es algo, Bergson, desde la lectura de Deleuze (2001), se distancia de la lectura del cine desde la fenomenología, pues de acuerdo con el autor en análisis:

La fenomenología, en ciertos aspectos, sigue fijada a unas condiciones pre-cinematográficas que explican su ambigua postura: ella confiere a la percepción natural un privilegio que hace que el movimiento siga todavía vinculado a las poses 
(simplemente existenciales en lugar de esenciales); de ahí que se acuse al movimiento cinematográfico de ser infiel a las condiciones de la percepción, pero también que se lo exalte como un nuevo relato capaz de "acercarse" a lo percibido y a lo percipiente, al mundo y a la percepción (Deleuze, 2001, p. 89).

Nuestra percepción y nuestro lenguaje distinguen cuerpos (sustantivos), cualidades (adjetivos) y acciones (verbos). Pero las acciones han sustituido ya el movimiento por la idea de un lugar provisional al que este se dirige, o de un resultado que él obtiene; y la cualidad ha sustituido el movimiento por la idea de un estado que persiste a la espera de que otro lo reemplace; y el cuerpo ha sustituido el movimiento por la idea de un sujeto que lo ejecutaría, o de un objeto que lo padecería, o de un vehículo que lo transportaría (Deleuze, 2001, p. 92). De aquí se desprende que existan imágenes semejantes: imágenes-acción ${ }^{2}$, imágenes-afección ${ }^{3}$, imágenes-percepción ${ }^{4}$.

\section{La imagen movimiento en el cine: Vollet}

Según Vollet (2006), por ejemplo, en la primera forma (imagen-movimiento) la película mostraba un continuo de movimientos que relacionaban una situación con acciones surgidas de ésta situación y la cambiaban; todo esto encuadrado en un todo que le daba un margen fijo... de percepciones o situaciones brotan acciones, y estas a su vez, cambian percepciones o situaciones (p. 75). De esta forma, las imágenes

2 Algunos aspectos de este apartado se retomaron del informe de investigación mencionado al comienzo del escrito a pie de página y son producto de esa investigación.

3 Se pasa insensiblemente de la percepción a la acción. "Es el segundo aspecto material de la subjetividad" (Deleuze, 2001, p. 99). Y así como la percepción vincula el movimiento a cuerpos (sustantivos), es decir, a objetos rígidos que van a servir de móviles o de cosas movidas, la acción vincula el movimiento a actos (verbos) que serán el trazado de un término o de un resultado supuestos.

4 Se da en intermedio de las dos primeras imágenes anunciadas anteriormente. Ella surge en el centro de indeterminación, es decir, en el sujeto, entre una percepción en ciertos sentidos perturbadora y una acción vacilante. Es una coincidencia entre sujeto y objeto, o la manera en que el sujeto se percibe a sí mismo, o más bien se experimenta o se siente por dentro (tercer aspecto material de la subjetividad). Lo anterior se justifica a partir del reconocimiento de que existen una serie de movimientos exteriores que nosotros absorbemos, refractamos y que no se transforman ni en objetos de percepción, ni en actos del sujeto, es decir, se transforman en la imagen-afección. La imagen afección deja de ser traslación para convertirse en movimiento de expresión. 
movimiento se pueden dividir en tres tipos: imagen-percepción (que dan una visión, una percepción global de la situación), imagen-acción e imagen-afección ${ }^{5}$.

Este continuo de movimientos e imágenes entra en crisis hacia la mitad del siglo XX, una destrucción que necesita de nuevas imágenes para su reconstrucción, lo cual se puede denominar como crisis de la imagen-movimiento, luego de la Segunda Guerra Mundial. Pero Deleuze, de acuerdo con Vollet (2006), encuentra una crisis global especialmente después de la Segunda Guerra Mundial, crisis física y psíquica... ya no hay coherencia interna entre las acciones... la realidad se dispersa en trozos heterogéneos y se convierte en cliché... el actor se vuelve un espectador... algunas de las películas de Hitchcock donde la totalidad cerrada percepción-acción se pone en cuestión hasta el límite del peligro, pues se introducen imágenes mentales... lo que ocasiona un cambio profundo en el cine hacia imágenes pensantes.

Así pues, las sensaciones ya no son sensorio-motóricas, sino situaciones-límite, es decir: situaciones que se viven como si uno fuera espectador sin poder de reacción que entonces solo se describen, pero ya no se vuelven acción. Así pues,

\footnotetext{
Se refiere a la percepción subjetiva unicentrada. Es de recordar que la percepción es como primera medida sensorio-motriz: "La percepción no está más en los centros sensoriales que en los centros motores, ella mide a complejidad de sus relaciones" (Deleuze, 2001, p. 98).
}

según Deleuze, el cine se vuelve una reflexión del tiempo, una presentación del tiempo en sí. (Un ejemplo actual: Matrix). El cine se cristaliza en tiempo actual y virtual... así se vuelve indistinguible, o indiscernible, como Deleuze lo llama, qué es lo actual y qué es lo virtual, el propio tiempo es un heterogeneidad sustancial que entra en escena (Vollet, 2006, p. 77), donde "el cine de la objetividad se ha convertido en el cine de la subjetividad, de la mera temporalidad en su forma de existencia en el ser humano" (Vollet, 2006, p. 91).

\section{Segundo campo analítico: cine, filosofía y educación: momentos de una historia en construcción}

Entre el cine, la filosofía y la educación se produce un encuentro ${ }^{6}$ relacional, que sobreviene cuando el cine emerge como una nueva forma de arte, de técnica y de síntesis de la modernidad, como un gran invento del siglo XX en el cual se pueden sintetizar las aspiraciones profun-

\footnotetext{
El oficial de caballería en una montaña, viendo que un grupo de indianos ataca a unas familias en sus carros. Situación en la cual surge una acción que se muestra en una imagen-acción, típicamente semilocal (el ataque de la caballería): la percepción lleva a una acción del centro de percepción del hombre actor. Pero hay situaciones que no se pueden resolver en reacciones: lo que pasa es entonces mostrado en imágenes afección, la inhibición de actuar se transforma en una afección (percepción del sí mismo por sí mismo), visible, ej., en la cara del actor, mujeres llorando (p. 88).
} 
das de una época, que quiso tomar la realidad, la naturaleza y al hombre como objeto de conocimiento y que a su vez creó unas formas de transmisión cultural a través de una poderosa máquina: la escuela. Esta relación modernidad/ciencia, ciencia/ transmisión, imaginación/representación, vida cotidiana/subjetivación, movimiento/pensamiento hacen que cine, filosofía y educación establezcan una profunda alianza que, aunque no declarada formalmente, se convierte en referente de los procesos educativos y de producción cinematográfica en el siglo XX. En palabras de Montiel (1999), en su obra Teorías del cine, referenciando algunos de los espectadores del primer cinematógrafo de Lumière, afirma que algunos de ellos no le percibían ninguna importancia científica, más bien afirmaban que podría servir a los fines generales del hombre y al desarrollo del pensamiento. De otra parte, se observa que el cine interesó inicialmente a los científicos, luego a los moralistas (educadores) y por último a los artistas, en este sentido el encuentro del cine y los procesos de formación se producen en el mismo momento que el cine aparece como posibilitador para la impresión de imágenes y darles movimiento. En este sentido aparecen dos tendencias iniciales en el estudio del cine, unos que creen en el cine como medio formativo, Ilamados los formalistas, y otros que apuntan al realismo y buscan que el cine muestre efectivamente la realidad.

Deleuze, siguiendo los trabajos de Bergson, afirma que el cine puede considerarse como un ejercicio del pensamiento desde la antigüedad, es decir, funciona con cortes inmóviles instantáneos y con un movimiento impersonal que está en el aparato que las reproduce, en la lógica de Bergson, se opera un cinematógrafo interior para producir el pensamiento. Lo característico del cine es la imagen-movimiento, no una imagen a la que se le da movimiento. En este sentido, el encuentro entre cine y filosofía se puede ubicar en las maneras como se percibe la realidad y como ella se construye a través inicialmente de imágenes-movimiento. Es así como los cortes inmóviles y la corrección de la imagen producen y asemejan un ejercicio del pensamiento sobre él mismo, es decir, una formulación creativa y reconstructiva de la realidad y del mundo.

El encuentro cine, filosofía y educación opera de igual forma en ciertas maneras como la educación la escuela formal y la universidad han utilizado el cine para diferentes fines. Desde espacios libres como los cine-foros universitarios hasta la utilización 
didáctica de los filmes en el aula para autores o temas concretos. Sin embargo, aún existe el menosprecio, la relativización de la imagen para la formación y el aprendizaje, "a pesar que nos encontramos en la era de la civilización audiovisual y convivimos con múltiples pantallas que van desde la gran pantalla cinematográfica hasta las micropantaIlas de nuestros teléfonos móviles, el conocimiento a través de la imagen es menospreciado" (Gispert, 2009, p. 13), y aunque muchos maestros intentan dialogar con estos nuevos lenguajes, prevalecen medios y estrategias tradicionales de transmisión y enseñanza.

En este sentido, podemos plantear que el cine como forma de pensamiento supera la concepción racionalista del mismo para ubicarlo también en el ámbito de la emocionalidad, así pues, lo audiovisual puede expresar comprensiones más cercanas del mundo, de nosotros mismos y de la cultura. Desde esta perspectiva, el cine se puede definir como "una experiencia abierta, siempre redescubriéndose y comprendiéndose a sí misma, huyendo permanentemente de las reglas que tratan de aprisionarla en alguna ley establecida" (Gispert, 2009, p. 17). Una experiencia que nace de la ciencia y la técnica, crea fantasías, produce sueños, afecta a los sujetos involucrados, reconoce sentimientos y crea condiciones para relaciones y comprensiones más profundas con el mundo y con el hombre mismo.
Una de las herramientas conceptuales que se ha utilizado para suscitar el encuentro cine, pedagogía y filosofía está esbozada en la obra del Julio Cabrera Cine: 100 años de filosofía, en la cual se proponen dos planos de acción metodológica: el primero hace referencia al enfoque, se propone pensar en compañía de algunos filósofos que él llama cinematográficos, entendida la expresión en términos de la relación de la razón y la emoción. Es decir, en la posibilidad de identificar algunos pensadores de la filosofía que en sus conceptos procuran un tratamiento no solo racional, sino afectivo y emocional. Algunos filósofos se pueden desde esta perspectiva definir como cinematográficos por "haber problematizado la racionalidad puramente lógica con la que el filósofo se ha enfrentado habitualmente al mundo, para hacer intervenir también, en el proceso de comprensión de la realidad, un elemento afectivo (o pático)" (Cabrera, 1999, p. 14). Estos filósofos (los logopáticos) no se limitan únicamente a teorizar o conceptualizar lo emocional, sino que en sus prácticas vitales y académicas vinculan las dos situaciones, no separan ni fragmentan, intentan producir en la razón el doble efecto para que las comprensiones y aprehensiones del mundo sean más heurísticas. Los experimentos en enseñanza de la filosofía han ido demostrando cómo el aprender a filosofar no se logra por medio de una aproximación externa, de un 
conjunto de contenidos como los que el maestro tradicional impartía, sino que el aprender se da en la experiencia propia, en el ejercicio no solo mental, sino emotivo con los conceptos. En términos de Cabrera, en el cine: "Lo emocional no desaloja lo racional: lo redefine" (1999, p. 16), es decir, lo incluye, lo articula y lo horizontaliza, lo ubica en el mismo nivel de importancia y de determinación.

El segundo plano de acción metodológica propuesto por Cabrera es el uso de la categoría concepto-imagen, que más que una definición acabada es un camino, un derrotero, una posibilidad para comprender y analizar las películas en clave de interacción y de encuentro. El concepto imagen, según Cabrera, tiene tres características centrales: la articulación lógica y sensibilidad, es decir, los conceptos imagen son presentados racional y sensiblemente al mismo tiempo; el concepto imagen debe producir un impacto emocional y, por último, intenta a través de la unidad de los elementos anteriormente descritos mostrar comprensiones singulares y universales, experiencias comprensivas del mundo y de la realidad.

El concepto imagen, a partir de la propuesta de Cabrera, como perspectiva filosófica de análisis del cine recorre ocho formas para constituirse:

1. En un primer momento, debe funcionar en el contexto de una experiencia concreta que lo defina y lo ubique en relación con formas y prácticas cotidianas, es decir, una experiencia que hace falta tener, que es necesaria. Lo racional de la imagen concepto puede ser expresado en palabras, pero solamente cuando lo que llamaremos en este texto estudiante/espectador ve la película, solo allí comprende el lugar del amor, del dolor, de la duda, de la nación, de la tierra o de la infancia. De igual forma, no es solo la experiencia la que lo constituye; de lo contrario se quedaría en el ámbito de la experiencia estética, es necesario el tamiz y análisis lógico del mismo. Sin alguno de los dos componentes el análisis es incompleto.

2. El segundo elemento hace referencia al impacto emocional que la experiencia instauradora produce. Este impacto está mediado por lo que el filme hace en el que lo ve: 
Que al mismo tiempo, le diga algo acerca del mundo, del ser humano, de la naturaleza, etc., que tenga un valor cognitivo, persuasivo y argumentativo a través de su componente emocional. No están interesados, pues, tan solo en una pura explosión afectiva por ella misma, sino en un abordaje... logopático, lógico y pático al mismo tiempo. Falta referencia

Es aquí donde razón y emoción se encuentran y se determinan mutuamente, se hacen una sola en el filme, es decir, la filosofía deviene cine y el cine deviene filosofía.

1. Los conceptos imagen son afirmativos en la medida que intentan proponer una particular manera de pensar en situaciones que puedan ser aplicadas en diversos contextos y situaciones, son apuestas por universalizar incluso en lo local. El concepto imagen singulariza y generaliza. En este sentido, el cine no elimina la interpretación y la construcción de la verdad, sino que está ya no mediado solamente por lo cognitivo-mental, sino por lo pasional, es decir, por la razón logopática. Además, Cabrera afirma que en el cine la universalidad y la verdad están en el ámbito de la posibilidad y no de la necesidad, y mucho menos de la esencialidad.

2. La localización de los conceptos imagen en el filme. No existe una fórmula definitiva para ubicarlos. No son simples escenas, pero una escena puede ser un concepto imagen, puede ser la banda sonora, la fotografía, los planos e infinidad de recursos y formas de la película. En este sentido, el concepto-imagen es la manera como los directores piensan sus trabajos y la forma como los espectadores logramos descifrarlos e interpretarlos.

3. Los conceptos imagen se pueden desarrollar en los elementos concretos literales de las películas, pero de igual forma en las abstracciones que el filme intenta proponer. Es decir, el concepto imagen puede emerger de la situación más normal y cotidiana ocurrida, pero también puede desarrollarse en diversos planos interpretativos: el ser, la dignidad, el hombre.

4. Los conceptos imagen no son categorías estéticas, no determinan si la película es buena o mala, pero pueden sugerir formas de compresión 
y asimilación de experiencias, situaciones, conceptos y teorías. Es decir, aquí no es tan importante si la película es clasificada o no como cine arte o como comercial, allí pueden existir perspectivas de comprensión filosófica en ciertos ámbitos de la realidad.

5. Los conceptos imagen no son exclusivos del cine, también son utilizados en la filosofía y la literatura.

6. Los conceptos imagen producen soluciones a las diferentes problemáticas de orden filosófico, desde el punto de vista lógico, epistemológico y moral.

\section{Tercer campo analítico: regularidades de uso del cine en el campo educativo?}

En este último campo analítico, que se presenta a manera de conclusiones, se intenta dar cuenta de algunas de las apropiaciones y usos del cine en el campo educativo.

\section{Primera regularidad: educación en valores y convivencia ciudadana a través del cine en relación con el arte}

En este primer campo de análisis se encuentran las investigaciones de Ortigosa (2002) y Urpi (2008). El primero realiza una investigación sobre la relación entre la educación en valores (léase para este autor educación moral) con el cine, asumiendo, entre otras, como categorías conceptuales la experiencia de la belleza en la educación moral y el sentido de las obras de arte en la educación, desde una lectura del pensamiento de Gadamer. Entre algunos de los aspectos teóricos que el autor en mención refiere se tienen la relación entre el

\footnotetext{
Siguiendo a Deleuze, un encuentro se convierte en un dinamismo en el cual los que hacen parte de él no buscan necesariamente un cierto tipo de filiación o un espacio para encontrar algunos referentes de identificación. El encuentro descrito no habla en representación de nadie ni representa a nadie, cada uno en él habla de sí mismo, de su cuidado, de su recorrido, de su territorio, de su vida y de su particular relación con el mundo. Es en ese hablar de sí mismo cuando ocurre en los individuos el más severo ejercicio de despersonalización, cuando se abre a las multiplicidades que lo atraviesan y a las intensidades que lo recorren. Por más que haya una relación o una interacción filosofía, cine y educación, hablamos en todo el texto de encuentro.
} 
cine y la práctica de los valores y disposiciones morales que permite en la vida humana, dado que:

La catarsis generada por la obra de arte contribuye a iluminar y a intensificar las situaciones vitales en las cuales acontece la práctica de los valores música, narraciones y cine, habitúan a los alumnos a juzgar con rectitud y a enorgullecerse de mantener disposiciones morales. En ese sentido, ver cine, cuando es análogo a la exposición que es la propia vida humana y permite acceso directo intenso y educativo a lo valioso (Ortigosa, 2002, p. 158).

Además del componente actitudinal en relación con la formación en valores, Ortigosa (2002) refiere "el papel de la acción dramática producida por los medios audiovisuales" (p. 166) teniendo en cuenta que "en los fundamentos del mundo audiovisual figura lo que bien puede llamarse (según Hegel) el espíritu objetivado de una sociedad y figura en términos de organización narrativa y dramática" (Ortigosa, 2002, p. 166). Lo anterior, dado que para el autor el cine y la televisión han sido vistos como medios y ficción para modificar el espíritu objetivado, bien en sentido económico, "creando y planificando culturas artificiales"(p. 168). Ahora bien, desde la operacionalización de la experiencia en mención, el autor elabora fichas técnicas de las películas junto con una sinopsis de las mismas, luego realiza una determinación de áreas y cursos que involucraría la experiencia y elabora un cuestionario procedimental para los estudiantes. A nivel metodológico, establece unos objetivos conceptuales y actitudinales, entre otros, el desarrollo del aprendizaje, el autocontrol y la autoconfianza.

Por su parte, en el contexto de la relación entre convivencia ciudadana y aprendizaje por medio del cine, Urpi (2008) asume como presupuestos teóricos la teoría pedagógica, la teoría estética del cine y el marco específico de educación para la convivencia, así pues, en este artículo:

Se muestra cómo aprovechar la vivencia del cine y el carácter sugerente de las imágenes para promover la adquisición vivencial de valores, actitudes y conductas relacionadas con la convivencia ciudadana. Se propone la película de animación Azur y Asnar para el último ciclo de primaria (9-12 años), justo cuando se da el paso al preadolescencia (p. 20). 


\section{Segunda regularidad: cine y educación social lectura crítica de contexto}

En este campo de análisis se sitúan las investigaciones de Perera (2005) y Botero y William (1995). Perera (2005) da cuenta del uso del cine como educación social, pues busca "mostrar cómo el cine puede ser un elemento claramente formativo, además de un apoyo metodológico en la intervención pedagógica, y hace incidencia en algunas profesiones que pueden aprovecharse del séptimo arte como soportes de complementación profesional" (p. 205). Según la autora en mención:

La historia y el desarrollo del cine como arte e industria y la pléyade de directores que han hecho películas que ayudan a la construcción de una escala de valores son argumentos suficientes para que podamos contar con el cine como un recurso didáctico para hacer una pedagogía más acorde con la realidad de los tiempos que vivimos (Perera, 2005, p. 205).

Además, en esta experiencia Perera (2005) asume el cine como "el arte social de nuestro tiempo" (p. 213) y apuesta por la "posibilidad de combinar cine y educación social desde una educación intercultural que aporte a la construcción de una ciudadanía intercultural" (ibíd.) donde se comprenda cómo "la cultura escrita y la cultura audiovisual colaboran en la formación de la persona" (ibíd.).

En la parte operativa de la experiencia se da cuenta de la creación de guías didácticas cinematográficas, se escogen tres categorías de análisis: adultos y vejez, educación social especializada, animación sociocultural, luego establecen las relaciones entre ámbitos, películas (El cartero, Cartas a Iris, El río de la vida, Mar adentro, Balseros, En algún lugar de África, entre otras) y valores sociales (libertad, justicia, respeto, comprensión, entre otros).

El proyecto de investigación, denominado "Formación en valores de los alumnos a través del cine-club", fue desarrollado por Botero y William (1995) en Sabaneta. En esta propuesta se buscó realizar un pilotaje de la formación en valores a través del cine-club con una amplia participación de los padres de familia y la comunidad cercana a las instituciones donde se desarrolló la experiencia; entre otras, Escuela Especial Rubén Piedrahita Arango, de Yarumal, y la Escuela Nueva Buenaventura, del municipio 
de Toledo. Entre los objetivos propuestos se tiene:

Presentar una alternativa pedagógica encaminada a la vivencia de los valores de justicia, respeto $y$ tolerancia al interior de la comunidad educativa integrando contenidos del saber escolar y popular para fundamentar conceptual y didácticamente el proyecto de cine-club y potenciar el papel que cumplen los medios de comunicación, especialmente el cine como agente socializador de valores (Botero y William, 1995, p. 7).

En esta experiencia se trabajan cuatro concepciones que actúan como ejes de fundamentación, la primera tiene que ver con la concepción del hombre, pues para el proyecto de cine-club el hombre se concibe:

Como una totalidad integrada por distintas esferas, entre ellas lo biológico, lo cultural y lo social mediatizado por diversas intencionalidades que lo convierten en un ser cargado de significaciones, que le confieren la capacidad de tomar decisiones que le ayudan a construirse a sí mismo y a transformar su grupo social (Botero y William, 1995, p. 5).

La segunda y la tercera tienen que ver con la concepción de educación y de sociedad, frente a estas la propuesta asume como "los principios epistemológicos del proyecto cine-club: corrientes pedagógicas, teoría del conocimiento, la acción comunicativa discursiva y la teoría de la resistencia" (Botero y William, 1995, p. 7). Así pues, se trata de una experiencia donde "desde lo formal se busca conectar espacios formales con espacios informales (comunidad, padres de familia), pues se deben integrar los contextos familiares, barriales, locales con un sentido de compromiso intelectual y social" (Botero y William, 1995, p. 19).

\section{Tercera regularidad: el cine como innovación educativa y experiencia didáctica}

En este tercer campo de análisis se sitúa la investigación de Rodríguez (2009), que da cuenta del cine como una estrategia para el desarrollo del pensamiento en el marco de realización de una experiencia de innovación educativa. El objetivo general de la investigación es diseñar una estrategia pedagógica que permita hacer rupturas con la imagen dogmática del pensamiento en los estudiantes universitarios por medio del cine; con tal motivo, y como objetivo específico, se optará por la construcción de unos referentes teórico-conceptuales que permi- 
tan sustentar que el cine se puede utilizar como una innovación para el desarrollo del pensamiento y elaborar una metodología a través de actividades y prácticas con los estudiantes.

La investigación de Rodríguez (2009) se inscribe en una metodología de corte cualitativo con un enfoque socio-crítico de investigación-acción, fundamentada en las teorías de Habermas. La población estuvo constituida por nueve estudiantes del programa de Psicopedagogía de la UPTC, integrantes del semillero del grupo de investigación Rizoma. Se realizó una prueba piloto en varias etapas o momentos, primero se seleccionaron cuatro películas: La lengua de las mariposas, Batman, el caballero de la noche, y Memento. Los criterios de esta selección están fundamentados en que son películas de tipo comercial, es decir, no necesariamente están catalogadas como cine arte o cine conceptual, la propuesta es que este modelo, basado en el concepto-imagen, puede ser aplicado a cualquier tipo de película, pues el cine, al estar constituido por imágenes, nos permite conjugar conceptos y emociones, como ya se ha demostrado en los referentes teórico-conceptuales fundamentados en Cabrera, De la Torre, Deleuze y Badiou.

En un segundo momento, se hizo una reunión con los estudiantes que intervinieron en el ejercicio para explicarles el sentido de la práctica, los objetivos, la metodología del trabajo, algunos conceptos sobre el cine y técnicas cinematográficas como el concepto de planos, movimientos de cámara, secuencias, entre otras. También se les indicó las películas a observar. Tercer momento, conversatorio (dimensión comunicativa). Cuarto momento, análisis de la información, las categorías objeto de análisis se eligieron teniendo en cuanta la naturaleza de la investigación, el tema, los objetivos y los instrumentos seleccionados fueron tres: concepto-imagen, categorías emergentes y formas de pensamiento.

\section{Cuarta regularidad: relación cine literatura}

Aquí se pueden situar los trabajos de Alfonso y Sammy (2008) y Valdelamar y Solanny (1993). En la primera investigación se propone una experiencia audiovisual que busca generar acercamientos entre la literatura y el cine; en sus palabras esta experiencia "tiene como finalidad aproximar los clásicos de la literatura al alumnado del segundo ciclo de la ESO y del bachillerato, al mismo tiempo contribuyendo a la educación en co- 
municación audiovisual" (p. 59). Plantean como centro de interés la realización de un corto cinematográfico, con la participación de 15 a 20 estudiantes. Se trata de una formación audiovisual que les permita una relación crítica con lo que ven:

Dado que muchas películas tienen su origen en una obra literaria, y que la literatura al contrario que la educación audiovisual sí forma parte del currículo escolar, una forma de aumentar la educación audiovisual, a la vez que el gusto por la lectura, es participar en la relación entre cine y literatura pasando del texto literario al cine, a la vez que se desarrolle el proceso de filmación de una película (Alonso y Sammy, 2008, p. 59).

Por su parte, el proyecto de investigación denominado "Cine y literatura. Análisis de las películas: Alas de libertad y El beso de la mujer araña", realizado por Valdelamar y Solanny (1993), da cuenta de la relación cine y literatura a partir de ubicar que la percepción del espectador puede partir de "un mundo que se organiza como relato" (el cine) o de:

"Un relato que se organiza como mundo" (la literatura); la relación

se establece en el caso de la autora por su gusto hacia lo literario y su pasión por el cine en sus palabras "al terminar mis estudios secundarios empecé a tomar clases, a ver películas ... al ingresar a la universidad aumentó mi inquietud y realicé estudios de investigación para relacionarlos con la pedagogía y la lingüística. Esto me llevó a reconocer la importancia del cine, sus posibilidades en la enseñanza y la necesidad de estudiar el lenguaje cinematográfico" (p. 81).

Esta investigación se asume desde el análisis de varios referentes, en primer lugar, el manejo del tiempo, frente a este sustenta que el cine es un lenguaje y se considera que:

Posee un poder de síntesis mucho mayor que el de la literatura, pues introduce más información y desarrolla arte en movimientos contrarios, además plantea que el cine propone un manejo del tiempo presente y la narrativa del tiempo pasado (Valdelamar y Solanny, 1993, p. 85).

En segundo lugar, la cuestión de la simultaneidad en tanto idea fuer- 
temente ligada a la de duración y secuencialidad de los planos, finalmente, analiza la cuestión de la recreación del pasado y la ilusión de realidad, pues "gracias a las imágenes en movimiento del cine pueden jugar con el tiempo y, por tanto, con la realidad objetiva, ya que las imágenes se mueven del presente al pasado y aun al futuro sin orden lógico, sin explicación" (Valdelamar y Solanny, 1993, p. 90). Por último, es importante anotar que la parte de la narrativa la manejan desde un monólogo interior, con el cual se da la posibilidad de recrear al personaje en su interior de una manera más profunda, pues "el monólogo recrea el tiempo del yo, diferente al tiempo categorial (o tiempo objetivo), por el cual nos regimos normalmente" (Valdelamar y Solanny, 1993, p. 95).

\section{A manera de cierre}

Finalmente, se puede ver cómo estas apropiaciones o usos que se muestran en este último apartado dan cuenta de las interrelaciones conceptuales mencionadas en la parte introductoria del artículo, y que ahora se expresan en el nivel de la práctica; dichas interrelaciones ponen en evidencia las formas de interacción entre pedagogía y didáctica en el uso del cine en las prácticas pedagógicas tanto en escenarios formales como no formales; entre filosofía, política y estética desde los procesos de formación que se agencian en las apropiaciones experienciales que se dan a través del uso del cine en el campo educativo; $y$, finalmente, entre pedagogía y formación sociopolítica, pues en varias experiencias se observa el funcionamiento del uso del cine para la formación ciudadana y de sujetos sociales críticos.

Además, más allá de los procesos de experienciación que se pueden lograr con el uso del cine en el campo educativo, muy ligado a la pedagogía, se observa la necesidad de repensar este campo a través de la lectura de autores como Benjamin y Deleuze, para reflexionar y reposicionar el problema del aquí y el ahora en la cotidianidad de la praxis educativa, las implicaciones filosóficas del uso del cine y arte en el campo educativo, los efectos en el sujeto maestro al entender el cine solo como un mecanismo, la posibilidad de los sujetos (estudiantes y maestros) de hacer experienciación de sí a través del cine, la crítica que desde el cine se puede hacer al empobrecimiento de la percepción de lo real y las realidades, al igual que el uso de la imagen pensamiento, entre otras. 
Por ello, se considera que estas formas de pensamiento permiten desde sus particularidades filosóficas interrogar varios de los usos "instrumentales" que rondan las apropiaciones del cine en el campo educativo contemporáneo y potencializar las implicaciones de su apropiación en la generación de pensamiento y de experienciación de sí desde los sujetos implicados en el acto educativo.

\section{Referencias}

Benjamin, W. (1989). La obra de arte en la época de su reproductibilidad técnica. En Discursos interrumpidos I, Buenos Aires: Taurus.

Botero, M. \& William, D. (1995). Formación en valores de los alumnos a través del cine-club. Medellín (Sabaneta): CINDE.

Cabrera, J. (1999). Cine: 100 años de filosofía. Una introducción a la filosofía a través del análisis de películas. Barcelona: Gedisa.

Deleuze, G. (2001). La imagen-movimiento: Estudios sobre el cine 1. España: Paidós.

Gispert, E. (2009). Cine, ficción y educación. Barcelona: Laertes.

Montiel, A. (1999). Teorías del cine. Barcelona: Montesinos.

Ortigosa, S. (2002). Educación: valores a través del cine y las artes. Revista Iberoamericana de Educación, (24), pp. 157-175.

Perera, D. C. (2005). Cine y educación social. Revista de Educación, (338), p. 205.
Rodríguez, L. (2009). El cine: una estrategia para el desarrollo del pensamiento. Tesis de Maestría, Universidad Pedagógica y Tecnológica. Tunja.

Rodríguez, V., Peñuela, D., Osorio, A. et ál. (2011). El cine como posibilidad de pensamiento desde la pedagogía: una mirada a la formación de maestros. Informe final proyecto de investigación CIUP. Grupo Pedagogía y Política. En proceso de publicación.

Urpi, C. (2008). La convivencia ciudadana aprendizaje por medio del cine. Aula de Innovación Educativa, 15(177), pp. 64-67.

Valdelamar, C. y Solanny, Y. (1993). Cine y literatura. Análisis de las películas: Alas de libertad y EI beso de la mujer araña. Trabajo de pregrado (Licenciatura en Español e Inglés). Universidad Pedagógica Nacional.

Vollet, M. (2006). Imágenes, percepción y cine en Bergson y Deleuze. Eidos, Revista de filosofía de la Universidad del Norte, (005).

Este último apartado retoma, como se mencionó al comienzo del artículo, algunos aspectos del proyecto El cine como posibilidad del pensamiento desde la pedagogía: una mirada a la formación de maestros, trabajado por los investigadores del grupo Pedagogía y Política, el cual se encuentra en proceso de publicación por la UPN. 